\title{
Emerging biogenesis technologies of extracellular vesicles for tissue regenerative therapeutics
}

Journal of Tissue Engineering Volume 12: 1-13 (C) The Author(s) 2021 Article reuse guidelines: sagepub.com/journals-permissions DOI: $10.1177 / 20417314211019015$ journals.sagepub.com/home/tej

(S)AGE

\author{
Jung-Hwan Lee $e^{1,2,3,4,5,6}$ iD, Ji-Young Yoon ${ }^{1,2}$, Jun Hee Lee 1,2,4,5,6, \\ Hae-Hyoung Lee ${ }^{1,3,6}$, Jonathan C Knowles ${ }^{6,7,8}$ (D) \\ and Hae-Won Kim ${ }^{1,2,3,4,5,6}$ iD
}

\begin{abstract}
Extracellular vesicles (EVs), including exosomes, carry the genetic packages of RNA, DNA, and proteins and are heavily involved in cell-cell communications and intracellular signalings. Therefore, EVs are spotlighted as therapeutic mediators for the treatment of injured and dysfunctional tissues as well as biomarkers for the detection of disease status and progress. Several key issues in EVs, including payload content and bioactivity, targeting and bio-imaging ability, and mass-production, need to be improved to enable effective therapeutics and clinical translation. For this, significant efforts have been made recently, including genetic modification, biomolecular and chemical treatment, application of physical/mechanical cues, and 3D cultures. Here we communicate those recent technological advances made mainly in the biogenesis process of EVs or at post-collection stages, which ultimately aimed to improve the therapeutic efficacy in tissue healing and disease curing and the possibility of clinical translation. This communication will help tissue engineers and biomaterial scientists design and produce EVs optimally for tissue regenerative therapeutics.
\end{abstract}

Keywords

Extracellular vesicles, therapeutics, biogenesis technologies, tissue regeneration

Date received: 30 March 202I; accepted: 2 May 2021

\section{General properties, isolation, and utility of extracellular vesicles}

Extracellular vesicles (EVs) are a collection of naturally derived particles enveloped by a phospholipid bilayer and considered a major cellular secretome, enabling cellular communications via transmission of macromolecules. ${ }^{1}$ EVs are composed of multiple genetic or intracellular biomolecules such as nucleic acids (RNA, DNA), proteins, lipids, and metabolites. ${ }^{2}$ Among the components of EVs, microRNA (miRNA) has gained a lot attention. It is a small, noncoding RNA (about 22 nucleotides) and is well known to regulate post-transcriptional gene expression by binding to the region of mRNA and its degradation, upand down-regulating various biological activities of cells in proliferation, migration, differentiation, and disease progress. EVs are secreted from all types of cells such as osteoblasts, odontoblasts, chondrocytes, fibroblasts, endothelial cells, skeletal muscle cells, cardiomyocytes, keratinocytes, neurons, or other neuronal cells, hepatocytes, cancer cells, and immune cells. ${ }^{3}$ Besides, EVs can be isolated from all kinds of tissues and a wide range of body fluids, including blood, plasma, breast milk, urine,

\begin{abstract}
'Institute of Tissue Regeneration Engineering (ITREN), Dankook University, Chungcheongnam-do, Cheonan, Republic of Korea ${ }^{2}$ Department of Nanobiomedical Science \& BK2I FOUR NBM Global Research Center for Regenerative Medicine, Dankook University, Chungcheongnam-do, Cheonan, Republic of Korea

${ }^{3}$ Department of Biomaterials Science, College of Dentistry, Dankook University, Chungcheongnam-do, Cheonan, Republic of Korea

${ }^{4}$ Department of Regenerative Dental Medicine, College of Dentistry, Dankook University, Chungcheongnam-do, Cheonan, Republic of Korea ${ }^{5}$ Cell \& Matter Institute, Dankook University, Chungcheongnam-do, Cheonan, South Korea

${ }^{6}$ UCL Eastman-Korea Dental Medicine Innovation Centre, Dankook University, Chungcheongnam-do, Cheonan, Republic of Korea

${ }^{7}$ Division of Biomaterials and Tissue Engineering, Eastman Dental Institute, University College London, Royal Free Hospital, London, UK ${ }^{8}$ The Discoveries Centre for Regenerative and Precision Medicine, Eastman Dental Institute, University College London, London, UK
\end{abstract}

\section{Corresponding authors:}

Jung-Hwan Lee, Institute of Tissue Regeneration Engineering (ITREN), Dankook University, Chungcheongnam-do, Cheonan 31116, Republic of Korea.

Email: ducious@gmail.com

Hae-Won Kim, Institute of Tissue Regeneration Engineering (ITREN), Dankook University, Chungcheongnam-do, Cheonan 31 I 16, Republic of Korea.

Email: kimhw@dku.edu 
saliva, synovial fluid, bile, amniotic fluid, semen, and ascites fluid.

EVs are currently categorized based on the vesicle biogenesis and the difference in size and composition; (i) "exosomes" (30-150 nm) when multivesicular bodies preformed by reverse budding of endosomal compartment fuse with the cytoplasmic membrane, (ii) "microvesicles" $(150-1000 \mathrm{~nm})$ when shedding or budding of the cytoplasmic membrane occur, and (iii) "apoptotic bodies" (500-2000 nm) when outward membrane blebbing in cells happen especially during apoptosis process in contrast with other EVs, which are produced by healthy cells as a part of regular membrane turnover and exocytosis. Among the three types of EVs, exosomes and microvesicles, without a strict distinction between them, have been collected together for applications in regenerative medicine due to the apoptotic characteristics of the apoptotic bodies.

Initially, EVs were believed to have the role of packaging and release of unwanted cellular materials like garbage bags. However, recent accumulating studies have highlighted other informative and therapeutic roles of EVs that are similar to conventional cytokines and growth factors, which spurred the utilization of EVs for therapeutic purposes of many diseases. ${ }^{4}$ Furthermore, EVs are embedded in the extracellular matrix (ECM), which provides mechanistic insights into the mutual interactions of EVs and ECMs and the possible utility of EVs as an effective delivery tool through ECM to target cells. ${ }^{5,6}$

Significant efforts have thus been made to isolate EVs from various types of cells. In the isolation of EVs from cultured cells for regenerative medicine, it is recommended to use either a serum-free medium or EV-depleted serum-contained medium to minimize the effects of asgiven EVs in commercially available serum. Thus, the isolation of EVs with high efficiency without contaminating (matrix) proteins and cell debris is necessary to ensure the accurate biological function of EVs of interest. There are many current and commonly used methods of EVs isolation, and their pros and cons were well-reviewed elsewhere ${ }^{7}$; from the current widely used technique, ultracentrifuge-and-filtration that separates and concentrates EVs according to their density $(1.13-1.19 \mathrm{~g} / \mathrm{mL})$ and then filtrate, to other improved techniques such as microfluidics, asymmetric flow field-flow fractionation, and nano-flow cytometry. Among the EVs isolation techniques, the ultracentrifuge-and-filtration is the most widely used that can collect EVs with relatively confined size, but it needs large sample volume and is time-consuming. ${ }^{8-10}$ Microfluidics method requires low sample volume and cost, but the isolated EVs amount per time is limited. On the other hand, the asymmetric flow field-flow fractionation technique can collect EVs in a gentle, rapid $(<1 \mathrm{~h})$ and highly reproducible way, but the particle loss and variation in the size due to sticking to the barrier membrane should be improved. ${ }^{11}$ Lastly, the nano-flow cytometry method has shown the high fidelities in EVs sorting, but it has drawbacks such as swarm detection, detection of smaller vesicles than previously thought possible, and multiple sized EVs. ${ }^{12}$ To overcome the disadvantages for clinical translation and therapeutics, multiple methods have been combined such as ultracentrifuge-combined asymmetric flow field-flow fractionation. ${ }^{7,13,14}$ Many studies have reported the impact of storage temperature and freezing/ thawing cycles on the size and bioactivity of EVs and recommended $-80^{\circ} \mathrm{C}$ as a storage temperature and minimal freezing/thawing for maintaining therapeutic and cargo potential. ${ }^{15-17}$

EVs have a huge impact on various biological and medical fields (as shown in Figure 1). EVs can inform the disease status and thus are new biomarkers of many diseases, including cancers. EVs may also be used to interpret the biological phenomena, to elucidate the unknown mechanisms of cell-cell and cell-ECM interactions. EVs are emerging therapeutics with their key packaged genetic molecules (e.g. miRNA). Especially as the delivery carriers for therapeutic purposes, EVs have innate merits compared with other synthetic polymers or viruses, such as their naturally-derived biocompatible bi-lipid layer structure and less possibility for invoking negative immune responses. ${ }^{18-22}$ The other abilities of EVs, such as enabling modifications with various ligands, penetrating bloodbrain barrier, and cellular internalization, are beneficial for local or systemic delivery to target specific cell types. Thus, EVs have been spotlighted as versatile, tunable therapeutic tools for the healing and treatment of various traumatic injuries and diseases. ${ }^{23,24}$

In this context, recent efforts have been made to improve the preparation techniques of EVs, such as the genetic modification and specific drug/biomolecule treatment, during biogenesis process or at post-collection stages (as schemed in Figure 1). Furthermore, applying a biophysical and mechanical stimulus and providing 3D culture conditions with engineered biomaterials has been highlighted to improve the quantity and quality of EVs. ${ }^{4,25-}$ ${ }^{28}$ Our communication here will help tissue engineers and biomaterial scientists design and generate EVs optimally for tissue regenerative therapeutics.

\section{Key issues in the biogenesis of EVs}

Several key issues are considered in EVs' biogenesis: bioactivity (payload content), mass-production (quantity), targeting, and tracking. Firstly, EVs should contain bioactive components necessary for the therapeutic actions ("payload content/bioactivity" issue). However, native EVs have limited in their components, of which the content is mainly dependent on the donor cells and their microenvironment. Along with the quality of the contents, EVs should be mass-produced to achieve enough amount that allows clinically relevant treatment tools ("quantity/ 


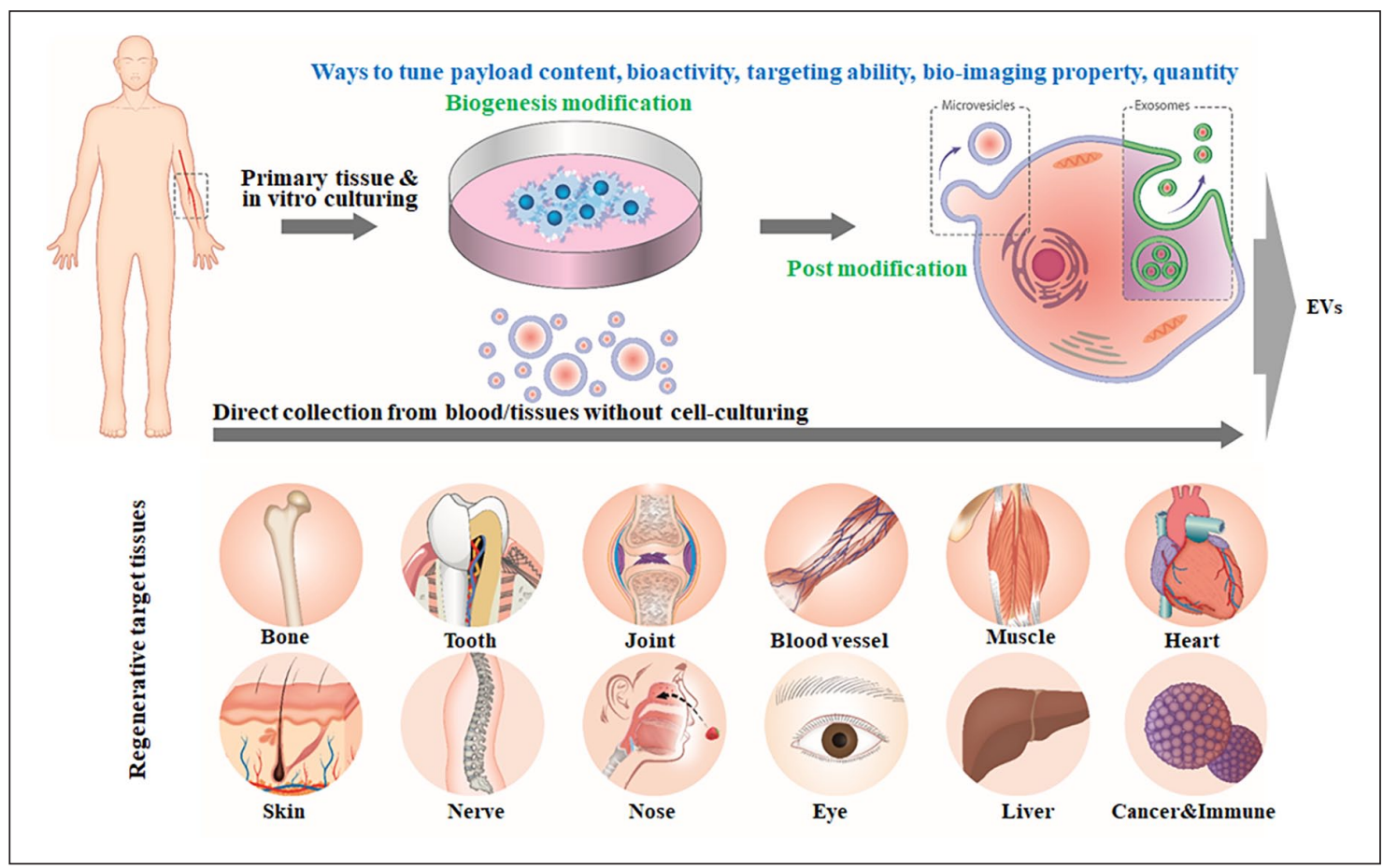

Figure I. Schematic showing the collection of EVs from various sources and their diverse applications for regenerative therapeutics. During or after biogenesis, various methods are used to tune/enhance the payload content, bioactivity, targeting ability, bio-imaging ability, and quantity.

mass-production" issue). To date, one significant hurdle is the limited amount of therapeutic EVs per cell, requiring massive in vitro cell cultures to gather enough quantities of EVs. $^{29}$

Besides, EVs should interplay with target cells and deliver their bioactive contents to the cells ("targeting" issue). Native EVs have some tropism depending on the epitopes expressed by the donor cells or the culture conditions of the cells (e.g. growth, inflammation, or differentiation condition), although the mechanism of the process was not fully understood yet. However, the tropism of EVs may not be enough to target tissues or cells for therapeutic purposes. Further engineering the EVs would help specifically targeting tissues or cells and even intracellular components. In association with the targeting is the retention of EVs in localized sites; for this, EVs should internalize cells effectively to deliver the bioactive cargo molecules and reside for a long period to elicit biological efficacy. However, native EVs have a limited endolysosomal escape, albeit better than synthetic carriers, limiting the capacity to release their contents without degradation of the bioactive cargo. When EVs are possible to visualize, that is, to allow tracking in vivo, the biodistribution and targeting efficacy can be easily monitored. Native EVs are not detectable; thus modification and labeling of EV's membrane without mitigating the innate bioactivity is needed. Fluorescence, luminescence, or radio-detector can visualize, monitor the delivery route, biodistribution, and targeting efficacy of EVs.
Over the last years, technologies to tackle the issues in EVs as mentioned above, that is, bioactivity (payload content), targeting and bio-imaging ability, and mass-production (quantity), have been significantly progressed. ${ }^{28}$ Here we discuss the most recent technological advances possible by the control of donor cells during or at a post-collection of EVs biogenesis, which includes genomic insertion, recapitulating $2 \mathrm{D}$ and $3 \mathrm{D}$ culture conditions, and applying biophysical and mechanical cues (as depicted in Figure 2 and summarized in Table 1).

\section{Payload content and bioactivity of EVs}

Increasing the bioactivity of EVs by the modulated payload content has been a key issue in the biotechnology of EVs for their therapeutic uses. Studies have been focused on modulating the culture microenvironments of EVssecreting donor cells, such as altering ingredients, oxidative stress, and physical cues. Specifically, EVs have been generated under different conditions, involving differentiation medium, ${ }^{30,31}$ hypoxia, ${ }^{32,33} 3 \mathrm{D}$ culture, ${ }^{34}$ mechanical force, ${ }^{35,63}$ and their combinations (e.g. 3D culture + mechanical force).${ }^{37}$ The key concept in the applications of those cues during the biogenesis of EVs is to allow cells to experience the conditions where the biochemical and biophysical conditions are mimicked or modulated to the native tissue microenvironments. Thus, the generated EVs can preserve the bioactivity of cells of interest. 


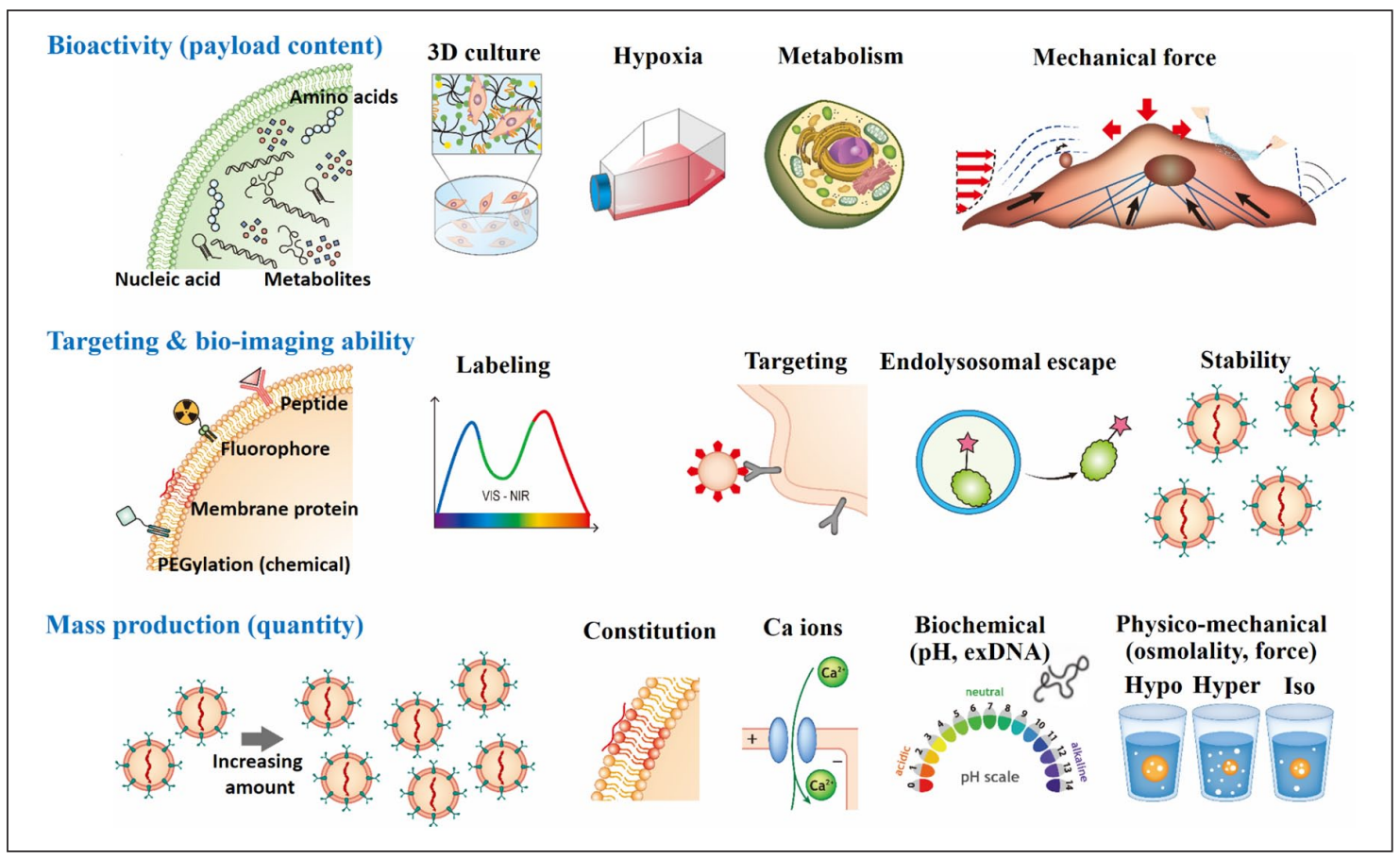

Figure 2. Schematic showing the recent technological efforts in solving some key issues in the biogenesis of EVs (bioactivity, targeting ability, mass production) utilizing various methods such as genomic insertion, recapitulating 2D and 3D culture conditions, and applying biophysical and mechanical cues.

One recent study by Wei et al. reported the effect of a specific differentiation medium on the biogenesis of EVs. EVs were collected at different stages (at day 5 and 11) during osteogenesis of mesenchymal stem cells (MSCs) in blood-derived hydrogels. The EVs secreted at an early stage of osteogenesis (at day 5) were shown to highly express the early osteogenic marker alkaline phosphatase (ALP). In contrast, those from a late-stage (at day 11) were rich in calcium phosphate crystals, implying the possibility of loading distinct cargo molecules within EVs by controlling the differentiation stage/period ${ }^{30}$ (Figure 3(a)). In another study with human adipose-derived stem cells (ASCs), the endothelial differentiation medium generated the EVs with higher miRNA-31 levels compared to the normal growth medium, which ultimately contributed to the increased endothelial cell migration, tubule formation, and aortic ring outgrowth. ${ }^{31}$ The approach of using a specific culture medium for the biogenesis of EVs is still in infancy, which yet can be potentially applicable to a variety of other situations where a specific payload of EVs is required to achieve the bioactivity of interest, such as for the lineage specification of stem cells, the polarization of immune cells, and rejuvenation of senescent cells.

Not only the culture medium ingredients, but oxidative stress is a key microenvironmental regulator of cells. Furthermore, when primary cells are cultured in vitro, they experience higher oxidative stress than those in vivo native tissues. Modulated oxidative stress conditions are often used to tune the cellular behaviors, including the secretome profiles. A pioneering study by Gray et al. reported that the EVs collected from cardiac progenitor cells cultured under hypoxia (versus those under normoxia) could increase the tubule formation of cardiac endothelial cells, reduce the pro-fibrotic phenotype of cardiac fibroblasts, and improve the in vivo function of the infarcted heart. ${ }^{32}$ When a hypoxia-conditioning was applied to MSCs, the EVs showed an increased vascular tubule formation in vitro without much difference in the concentration, size, and surface signatures compared to those with normoxia. ${ }^{33}$

As noted, most studies on EVs have been carried out in 2D culture dishes, which cannot replicate the native tissue 3D environments. A variety of engineered biomaterials (scaffolds and hydrogels) can thus be promising candidates for the $3 \mathrm{D}$ cultivation of cells, allowing them to experience tissue mimic "3-dimensionality" and then adopt the right signals in the biogenesis of EVs. A recent study by Rocha et al..$^{34}$ applied 3D cultures using a microwell array in the biogenesis of EVs. When compared with the EVs from the 2D tissue culture plate, the EVs from the 3D microwell array showed higher numbers per cell, and the contents of EVs, including small RNA, micro RNA, and proteins, were significantly altered by the 3D spheroid cultures (Figure 3(b)). This study delivers a key idea that the $3 \mathrm{D}$ cultures enable cells to generate more EVs while modulating the quality of EVs. However, the mechanisms underlying the EVs' biogenesis are yet to be elucidated. 
Table I. Summary of emerging biogenesis technologies of extracellular vesicles for tissue regenerative therapeutics.

\begin{tabular}{|c|c|c|c|c|c|}
\hline Purpose & Strategy & \multicolumn{3}{|c|}{ Key concept } & References \\
\hline \multirow{5}{*}{$\begin{array}{l}\text { Payload content } \\
\text { and bioactivity of } \\
\text { activity }\end{array}$} & $\begin{array}{l}\text { Modulating } \\
\text { the culture }\end{array}$ & \multicolumn{3}{|c|}{ Culture medium ingredients } & $\begin{array}{l}\text { Wei et al. }{ }^{30} \text { and Kang } \\
\text { et al. }{ }^{31}\end{array}$ \\
\hline & $\begin{array}{l}\text { microenvironment of } \\
\text { donor cell }\end{array}$ & \multicolumn{3}{|c|}{ Oxidative stress } & $\begin{array}{l}\text { Gray et al. }{ }^{32} \text { and Almeria } \\
\text { et al. }{ }^{33}\end{array}$ \\
\hline & & \multicolumn{3}{|c|}{ 3D culture (Microwell) } & Rocha et al..$^{34}$ \\
\hline & & \multicolumn{3}{|c|}{ Mechanical stretch } & $\begin{array}{l}\text { Najrana et al. }{ }^{35} \text { and Xiao } \\
\text { et al. }{ }^{36}\end{array}$ \\
\hline & & \multicolumn{3}{|c|}{ Combination (Mechanical force $+3 D$ culture) } & Yu et al. ${ }^{37}$ \\
\hline \multirow{13}{*}{$\begin{array}{l}\text { Quantity and } \\
\text { mass production } \\
\text { of EVs }\end{array}$} & $\begin{array}{l}\text { Modulating of } \\
\text { components/secretary }\end{array}$ & \multicolumn{3}{|c|}{$\begin{array}{l}\text { Modification of the components of the *ESCRT } \\
\text { machinery. }\end{array}$} & Colombo et al. ${ }^{38}$ \\
\hline & $\begin{array}{l}\text { machinery protein } \\
\text { of } E V s\end{array}$ & \multicolumn{3}{|c|}{$\begin{array}{l}\text { Enhancement of EVs proteins in donor cells using } \\
\text { lentivirus }\end{array}$} & Böker et al. ${ }^{39}$ \\
\hline & & \multicolumn{3}{|c|}{ Overexpression of**cortactin } & Sinha et al. ${ }^{40}$ \\
\hline & $\begin{array}{l}\text { Increasing the } \\
\text { intracellular } \mathrm{Ca} \text { ions. }\end{array}$ & \multicolumn{3}{|c|}{ Intracellular $\mathrm{Ca}$ ion enhancers } & $\begin{array}{l}\text { Messenger et al. }{ }^{41} \text { and } \\
\text { Shyonget al. }{ }^{42}\end{array}$ \\
\hline & Adjusting biochemical & \multicolumn{3}{|c|}{ Extracellular DNA } & Iliev et al. ${ }^{43}$ \\
\hline & cue & \multicolumn{3}{|c|}{ Liposomes concentration } & Emam et al. ${ }^{44}$ \\
\hline & & \multicolumn{3}{|c|}{ Proton concentration } & Parolini et al. ${ }^{45}$ \\
\hline & $\begin{array}{l}\text { Applying physico- } \\
\text { mechanical cues }\end{array}$ & \multicolumn{3}{|c|}{ Cyclic mechanical stretch } & $\begin{array}{l}\text { Najrana et al. }{ }^{35} \text {, Wang } \\
\text { et al. }{ }^{46} \text { and } Y u \text { et al. }{ }^{47}\end{array}$ \\
\hline & & \multicolumn{3}{|c|}{ High-frequency acoustic stretching } & Ambattu et al. ${ }^{48}$ \\
\hline & & \multicolumn{3}{|c|}{ Thermal/oxidative stress } & $\begin{array}{l}\text { Hedlund et al. }{ }^{49} \text { and King } \\
\text { et al. }{ }^{50}\end{array}$ \\
\hline & & \multicolumn{3}{|c|}{ Photodynamic treatment } & Aubertin et al. ${ }^{51}$ \\
\hline & & \multicolumn{3}{|c|}{ High-energy X-ray irradiation } & Jabbari et al. ${ }^{52}$ \\
\hline & & \multicolumn{3}{|c|}{ Cellular nanoporation } & Yang et al. ${ }^{53}$ \\
\hline \multirow{10}{*}{$\begin{array}{l}\text { Targeting and } \\
\text { bio-imaging } \\
\text { ability of EVs }\end{array}$} & $\begin{array}{l}\text { Post-treatment of EV } \\
\text { membrane }\end{array}$ & \multirow[t]{2}{*}{ Targeting } & \multicolumn{2}{|c|}{ Arginine rich cell-penetrating peptides } & $\begin{array}{l}\text { Nakase et al. }{ }^{54} \text { and } \\
\text { Nakase et al. }{ }^{55}\end{array}$ \\
\hline & & & \multicolumn{2}{|c|}{$\begin{array}{l}\text { Immobilization of PEG charged or neutral } \\
\text { liposome }\end{array}$} & Kooijmans et al. ${ }^{56}$ \\
\hline & & Imaging & \multicolumn{2}{|c|}{$\begin{array}{l}\text { Fluorophores, luminescence, reporters, or } \\
\text { radiotracers }\end{array}$} & $\begin{array}{l}\text { Tao et al. }{ }^{27} \text { and de Abreu } \\
\text { et al. }{ }^{28}\end{array}$ \\
\hline & $\begin{array}{l}\text { Genetic modification } \\
\text { of EV membrane }\end{array}$ & \multirow[t]{5}{*}{ Targeting } & \multirow[t]{2}{*}{ Cellular entry } & Magnetic nanoparticles & $\begin{array}{l}\text { Silva et al. } .^{57} \text { and } \\
\text { Heusermann et al. }{ }^{58}\end{array}$ \\
\hline & & & & $\begin{array}{l}\text { Cationic lipids, } \mathrm{pH}- \\
\text { sensitive peptides }\end{array}$ & Nakase and Futaki ${ }^{59}$ \\
\hline & & & \multirow[t]{2}{*}{$\begin{array}{l}\text { Intracellular } \\
\text { targeting of EV }\end{array}$} & $\begin{array}{l}\text { RGD/RII/Cell penetration } \\
\text { peptide }\end{array}$ & Jin et al. ${ }^{18}$ \\
\hline & & & & $\begin{array}{l}\text { CIC2 domain of milk } \\
\text { fat globule-EGF factor } 8 \\
\text { protein/transmembrane } \\
\text { domain of PDGFR }\end{array}$ & $\begin{array}{l}\text { Tabares and Betz }{ }^{60} \text { and } \\
\text { Nemec and Kilian }\end{array}$ \\
\hline & & & \multicolumn{2}{|c|}{$\begin{array}{l}\text { ECM } \\
\text { penetration }\end{array}$} & Hong et al. ${ }^{19}$ \\
\hline & & \multirow[t]{2}{*}{ Imaging } & \multicolumn{2}{|c|}{$\begin{array}{l}\text { A biotin receptor domain fused Gaussia } \\
\text { luciferase reporter }\end{array}$} & Lai et al. ${ }^{61}$ \\
\hline & & & A transgenic ind & cible GFP-EV reporter & Neckles et al. ${ }^{62}$ \\
\hline
\end{tabular}

*ESCRT: Endosomal sorting complex required for transport.

**Cortactin: Actin cytoskeletal regulatory protein.

Given the 3D culture used in that study is the aggregated form of cells, the recapitulation of 3D conditions with various engineered ECMs such as scaffolds and hydrogels might be more accurate to mimic the in vivo tissues, which remains a further research area.
Along with the 3D cultures, externally applied mechanical forces are known to regulate diverse cell behaviors (e.g. development, homeostasis, and repair), ${ }^{64}$ which is considered an effective way to alter the biogenesis process of EVs and ultimately to enhance the bioactivity. Recently, 


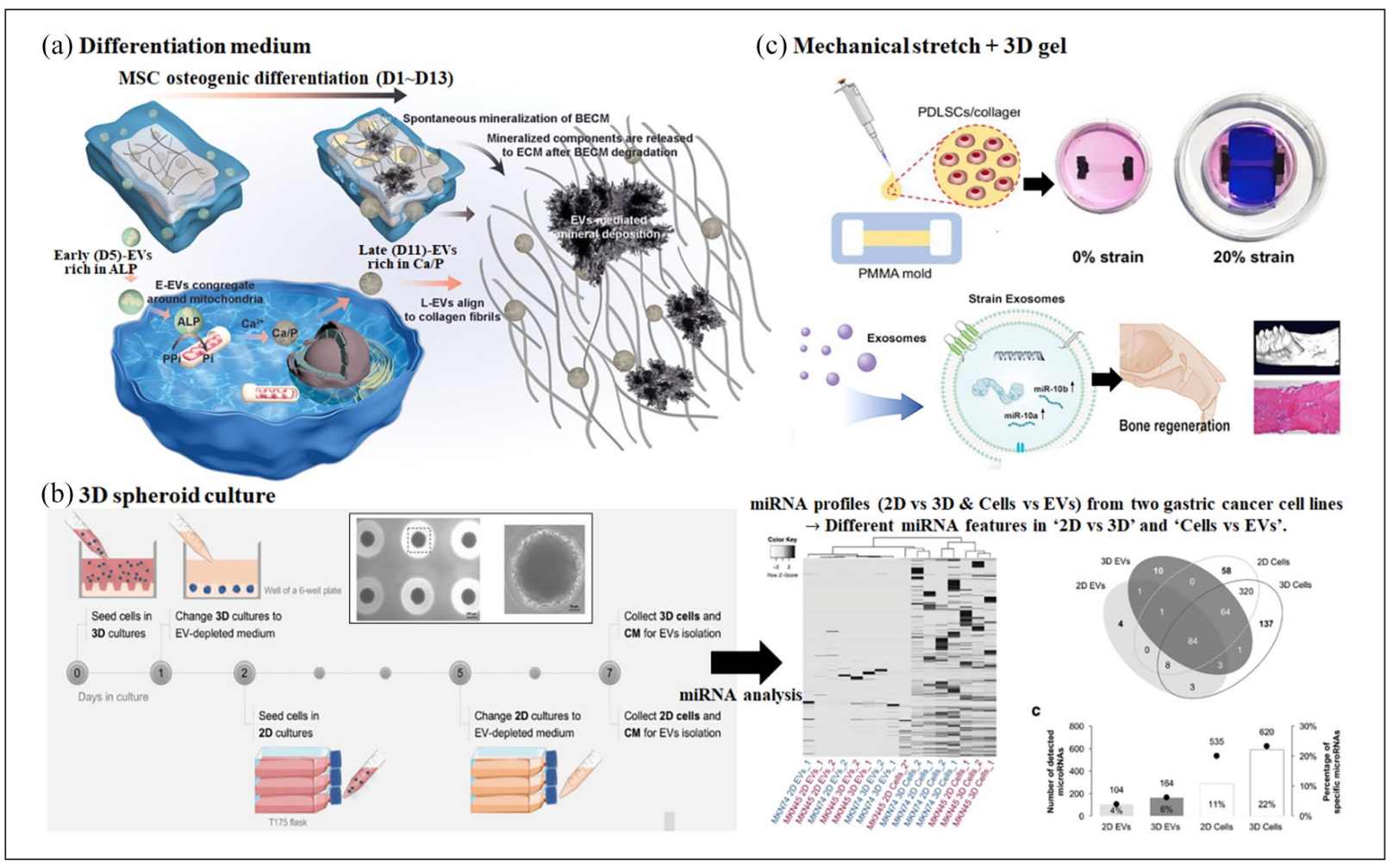

Figure 3. Strategies to enhance the bioactivity of EVs. EV-secreting donor cells are modulated by culturing under various conditions: (a) EVs gathered from MSCs at different culture time points in an osteogenic medium to enrich either ALP (early gathering) or $\mathrm{Ca} / \mathrm{P}$ (late gathering), (b) EVs obtained from stem cells under 3D spheroid culture condition to incorporate miRNAs with different profiles, and (c) EVs generated from periodontal ligament cells cultured under 3D gel matrix combined with mechanical stretch to enhance bone regeneration.

Adapted from Wei et al. ${ }^{30}$ in Adv Funt Mater, by Rocha et al. ${ }^{34}$ in Adv Sci, and by Yu et al. ${ }^{37}$ in Chem Eng J.

Najrana et al. ${ }^{35}$ reported that the mechanical stretch applied to lung epithelial cells could regulate the expression of specific miRNA in EVs. Both cyclic (10\%, 40 cycles $/ \mathrm{min})$ and continuous $(5 \%)$ mechanical stretch could regulate the miRNA profile in EVs more significantly than the control (w/o stretch), implying the mechanical conditioning would be a possibly effective way of generating EVs that contain miRNAs for therapeutic purposes. In another similar study with MSCs, the cyclically stretched cells synthesized EVs that could inhibit osteoclast differentiation. ${ }^{36}$ The event was demonstrated to relate with the attenuated RANKLinduced NF- $\kappa B$ signaling pathway, and the EVs could effectively rescue the in vivo osteoporosis caused by the unloading of the hindlimb, suggesting that the anti-osteoclastic role of endogenous MSCs in vivo might be due to the generation of stretch-induced therapeutic EVs. This study envisions mechanical conditioning as a potential strategy to collect therapeutic EVs from MSCs targeting diseases in skeletal systems.

Combinatory approaches of the above methods were further used to synergize the effects on the biogenesis of EVs. For example, Yu et al. ${ }^{37}$ applied mechanical force while culturing cells under 3D gel conditions (Figure 3(c)). Periodontal ligament MSCs cultured in a 3D collagen hydrogel containing magnetic nanoparticles could be mechanically stretched under a magnetic field. The 3D mechanical stimulation significantly altered the miRNA content in EVs compared to the 3D culture only, and the EVs-treated cells showed enhanced proliferation, migration, and osteogenesis in vitro and bone formation in vivo in an alveolar bone defect model. Although studies on the combinatory treatment are still in infancy, the possible synergistic or additive effects of the biomechanical cues with the optimized 3D matrix and biochemical environment (medium and oxygen tension) are envisaged that can lead to the generation of EVs with enhanced bioactivity and therapeutic efficacy, which remains a further exciting area of research.

\section{Quantity and mass production of EVs}

Increasing the quantity (mass production) of EVs is considered a significant challenge for their in vivo application and clinical translation. The strategies for mass-production of EVs include modulating the components or secretary machinery proteins of EVs, ${ }^{38-40}$ increasing the intracellular $\mathrm{Ca}$ ions, ${ }^{41,42}$ adjusting biochemical cues such as extracellular DNA, liposomes, and proton concentration, ${ }^{43-45}$ and 
applying physicomechanical cues such as forces ${ }^{35,46-48}$ and other stimuli (e.g. electricity, thermal, photodynamic, radiative stress). ${ }^{49-53}$

One of the effective ways to increase the EVs amount is the modulation of key biogenesis machinery components. For example, the endosomal sorting complex required for transport (ESCRT) was modified using RNA interference (RNAi) to target 23 different components of the ESCRT machinery individually. Results revealed a key role of a few selected members (SCR, VPS4B, ALIX, HRS, STAM1, TSG101) of this family in either the secretion efficiency or the size and composition of secreted EVs. ${ }^{38}$ In another study, when the expression of EVs constitutional proteins, that is, CD9, TSG101, and Alix in donor cells, was enhanced using lentivirus, the EVs amount and mean size were shown to increase. ${ }^{39}$ These results supported the concept that the modulation or overexpression of EVs compositional proteins would be beneficial for mass production. The key component protein in secretory machinery was tuned to boost the EVs secretion after the intracellular biogenesis in a different approach. The overexpression of actin cytoskeletal regulatory protein, cortactin, could promote exosome secretion by controlling branched actin dynamics without altering exosome cargo content, demonstrating a useful alternative way of targeting secretion machinery in the post-cellular-biogenesis to enhance the EVs production. ${ }^{40}$

An increase in intracellular $\mathrm{Ca}$ ions triggers the plasma membrane EV biogenesis, and the EV-production is dependent on the increased calcium mobilization and the activity of calpain, a calcium-dependent, non-lysosomal cysteine protease that modulates various cellular cascades, including $\mathrm{EVs}$ biogenesis. Thus, intracellular $\mathrm{Ca}$ ion enhancers (e.g. ionomycinor) were treated to donor cells during biogenesis. ${ }^{41,42}$ An acute elevation of intracellular calcium level stimulated an almost 5-fold increase in $\mathrm{CD} 63+, \mathrm{CD} 9+$, and ALIX+ EVs, general markers for EVs. Also, the EVs release was shown to depend on Munc13-4, an essential Ca ion-dependent synaptosomalassociated protein receptor that mediates vesicle fusion for the intracellular trafficking and exocytosis of intracellular granules such as secretory lysosomes and lytic granules. ${ }^{41}$ Unlike using calcium activator drugs, one recent study introduced $\mathrm{Ca}$ ion-releasing biomaterials (e.g. calcium phosphate nanoparticles) in mouse macrophage-like RAW264.7 and human monocyte-like THP-1 cells, which led to a significant increase in EVs secretion (more than twice) (Figure 4(a)). ${ }^{42}$ It was deduced that the calcium phosphate nanoparticles were internalized into cells and merged to acidic late-endosomes or lysosomes, resulting in membrane rupture and the release of $\mathrm{Ca}$ ions into the cytosol, which, however, warrants further investigation if the intracellular $\mathrm{Ca}$ delivery via nanoparticles would have the effect comparable to that though ion channels and would share the down-stream Ca signaling pathways.
Other exogenous biochemical cues, such as extracellular DNA, ${ }^{43}$ liposomes (neutral or cationic liposomes), ${ }^{44}$ or altered proton concentration, ${ }^{45}$ were also used during EVs biogenesis to increase the secretion. The extracellular DNA, genomic bacterial, eukaryotic DNA, or synthetic CpG-ODNs are known to induce higher secretion of vesicles in even non-immunomodulatory mammalian cells. ${ }^{43}$ Liposomes interact with the cell surface, also stimulating the generation of membrane vesicles, and among the liposomes, neutral, and cationic liposomes were shown to enhance the EVs secretion in a dose-dependent manner. ${ }^{44}$ Low $\mathrm{pH}$ (mild acidic, $\mathrm{pH}$ 6.0) also increased EVs release compared with a buffered condition (pH 7.0) in melanoma cells. ${ }^{45}$ Although it is not clear whether the $\mathrm{pH}$-dependent EVs secretion is only for $\mathrm{pH}$-sensitive cells such as cancer or immune cells or not, the positive roles of proton pump for EVs biogenesis and secretion might explain the $\mathrm{pH}-$ dependent EVs production phenomenon. ${ }^{60}$

Along with the biochemical, molecular cues, the biophysical forces and matrix stimuli have recently been proved to enhance the EVs secretion. When cyclic $(10 \%$, 40 cycles $/ \mathrm{min}$ ) mechanical stretch was applied to lung epithelial cells, a 2-fold change of EVs production was noticed with respect to non-stretched cells. ${ }^{35}$ The cyclic stretching $(20 \%$, ten cycles/min) of periodontal ligament stem cells also increased the EVs secretion by 30 -fold, which could decrease the nuclear translocation of NF- $\mathrm{KB}$ and IL-1 $\beta$ production in LPS-inflamed macrophages. ${ }^{46} \mathrm{~A}$ study by Yu et al. ${ }^{47}$ suggested a possible mechanism underlying the EVs stimulation by the mechanical stretch. Stretched MSCs were shown to enhance the TNF- $\alpha$ production and its endocytosis, which is a key feedback event to promote the MSC function and EVs secretion. From an in vivo experiment in the hindlimb, the mechanical unloading was revealed to cause MSC functional decline and bone loss, suggesting a strong role for mechanical force in increasing the EVs secretion in vivo. Other mechanical forces have also been introduced to cells, such as acoustic vibration, to increase the EVs secretion (Figure 4(b)). ${ }^{48}$ When a high-frequency acoustic vibration $(10 \mathrm{MHz})$ was applied to cells using an electrical stimulating piezoelectric device, the EVs were produced significantly more (15 times) when compared to non-vibration conditions. The higher EVs production was reasoned to the increased influx of calcium ions. ${ }^{48}$ The external mechanical stimuli might alter the cell membrane mechanics and the ion channels, and the intracellular mechanosensitive machineries that are involved in the EVs genesis, ${ }^{25,65-67}$ which yet needs future investigation.

Other biophysical cues such as electricity, thermal, photodynamic, and radiative stress were also applied to increase the EVs secretion. ${ }^{49-53}$ Thermal $\left(40^{\circ} \mathrm{C}\right)$ and oxidative stress $\left(50-100 \mu \mathrm{M}\right.$ of $\left.\mathrm{H}_{2} \mathrm{O}_{2}\right)$ induced a $20 \%-70 \%$ increase in overall EV production and a $50 \%-200 \%$ increase of functional NKG2D-bearing EVs in leukemia/ 
(a) CaP nanoparticles delivery

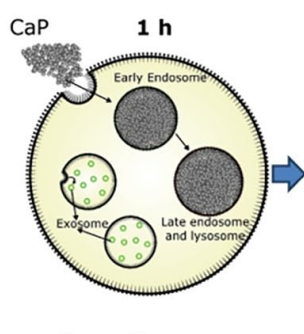

Raw cells
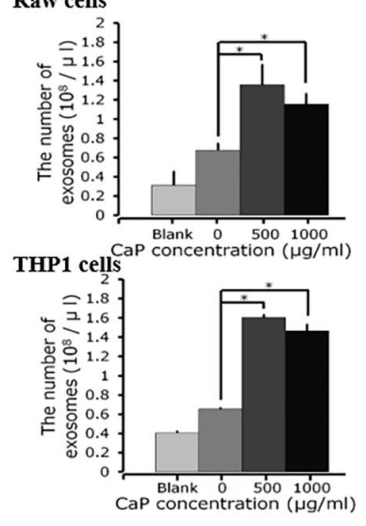

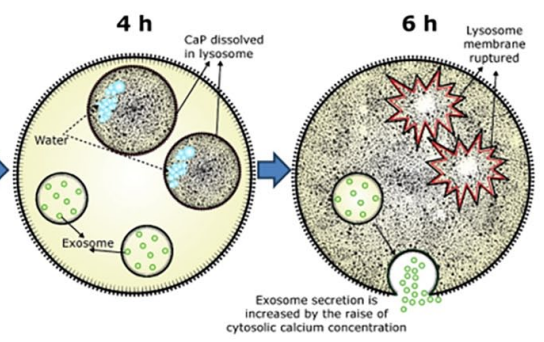

Exosome secretion is
increased b the raise of
cytosolic calcium concentration
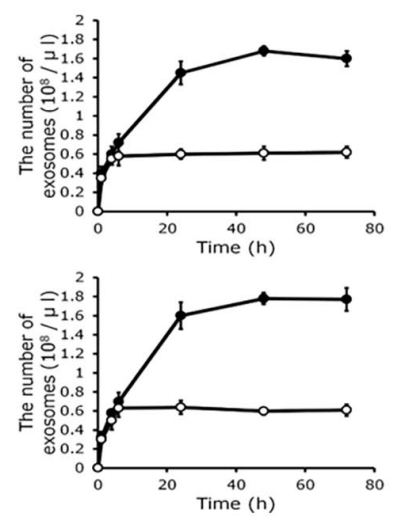

(b) High frequency stimulation
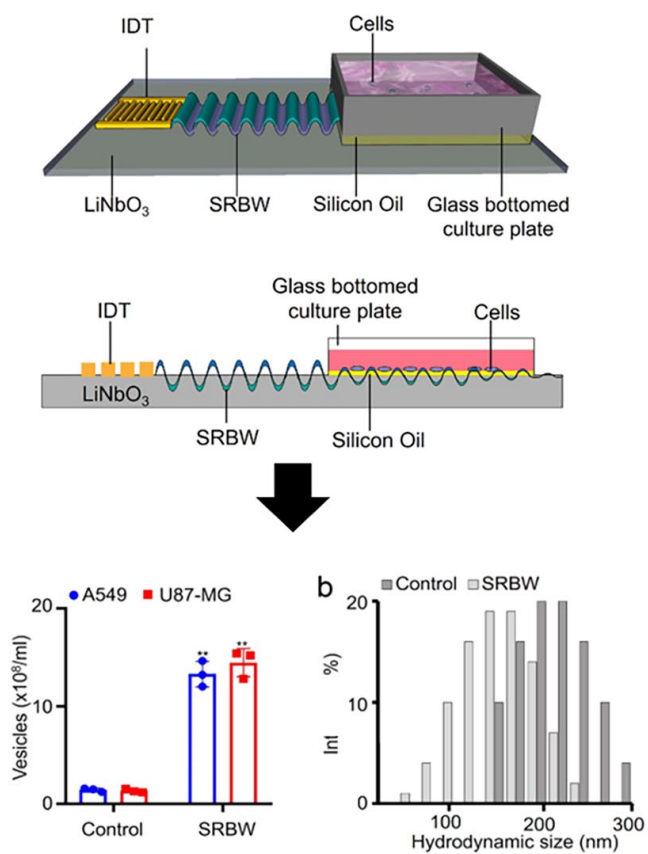

Figure 4. Strategies to increase the quantity of EVs secreted from cells: (a) application of calcium phosphate particles to mouse macrophage-like RAW264.7 and human monocyte-like THP-I cells increased the EVs quantity more than twice and (b) highfrequency acoustic stretching to cells increased the EVs quantity by I5-fold.

Adapted from Shyong et al., ${ }^{42}$ in Coll. Surf. B: Biointerf and by Ambattu et al. ${ }^{48}$ in Commun. Biol.

lymphoma T and B Cells, which led to enhanced immunosuppression. ${ }^{49}$ When the oxidative stress was maintained at a low level in a chamber $\left(0.1 \%-1 \% \mathrm{O}_{2}\right)$, the EVs production was significantly increased to $50 \%-100 \%$ in a HIF- $1 \alpha$-dependent pathway. ${ }^{50}$ Photodynamic therapy is one of the emerging regenerative treatments that use lowenergy light and photosensitizing chemicals. When photodynamic treatment $(1 \mathrm{~h})$ with Foscan ${ }^{\circledR}$ photosensitizer was performed on cells or in vivo tissues, an approximately 400 -fold increase in EVs number was detected compared to without treatment. ${ }^{51}$ A high-energy $\mathrm{X}$-ray $(2,4,6,8$, and $10 \mathrm{~Gy})$ irradiation was also shown to increase the EV production by $30 \%-100 \%$ in an intracellular ROS-dependent manner. ${ }^{52}$ Recently, the cellular nanoporation method was also reported to enhance the EVs secretion. Compared to bulk electroporation and other exosome-production strategies $\left(1 \% \mathrm{O}_{2}\right.$ hypoxia and $42^{\circ} \mathrm{C}$ thermal stress), the cellular nanoporation using a biochip made of $500 \mathrm{~nm}$ diameter of nanochannels could generate more exosomes (50-fold) as well as increased the designed cargo mRNA loading in EVs $\left(10^{3}\right.$-fold $) .{ }^{53}$

There should be possible mechanotransduction signaling pathways underlying the events in EVs production related to the applied physico-mechanical stimuli. A recent high-throughput screening study revealed that human MSCs could be mechanically conditioned to enhance vascular regeneration in vivo via the mechanosensitive signaling pathways (YAP and Smad2/3) that can be possibly engaged in the EVs production. ${ }^{68}$ From a metabolism point-of-view, mechanical cues have a potential impact on the synthesis of lipids, a major component of EVs, via activation of lipin-1 phosphatidic phosphatase, suggesting the implication of mechanical cues in EVs secretion through altered cellular metabolism. ${ }^{69}$

\section{Targeting and bio-imaging ability of EVs}

Targeting cells with EVs allows the determination of their in vivo journey and biodistribution as well as enhances the therapeutic effects with reduced doses. Some recent studies on EVs have underscored this area of targeting by posttreatment of EV membrane ${ }^{54-56}$ or genetic modification. ${ }^{18,19,70,71}$ While targeting is important to localize EVs, the retention at the lesion sites for a certain (long) period can enhance the bio-imaging properties. Thus, many methods were developed to enhance the systemic biodistribution $^{56,57}$ and cellular internalization. ${ }^{54,55,58,59}$ Detailed descriptions of the targeting strategies can also be referred to elsewhere. ${ }^{72}$ Earlier studies have tagged the EVs lipid membrane with fluorophores, luminescence reporters, or radiotracers at post-collection for the 


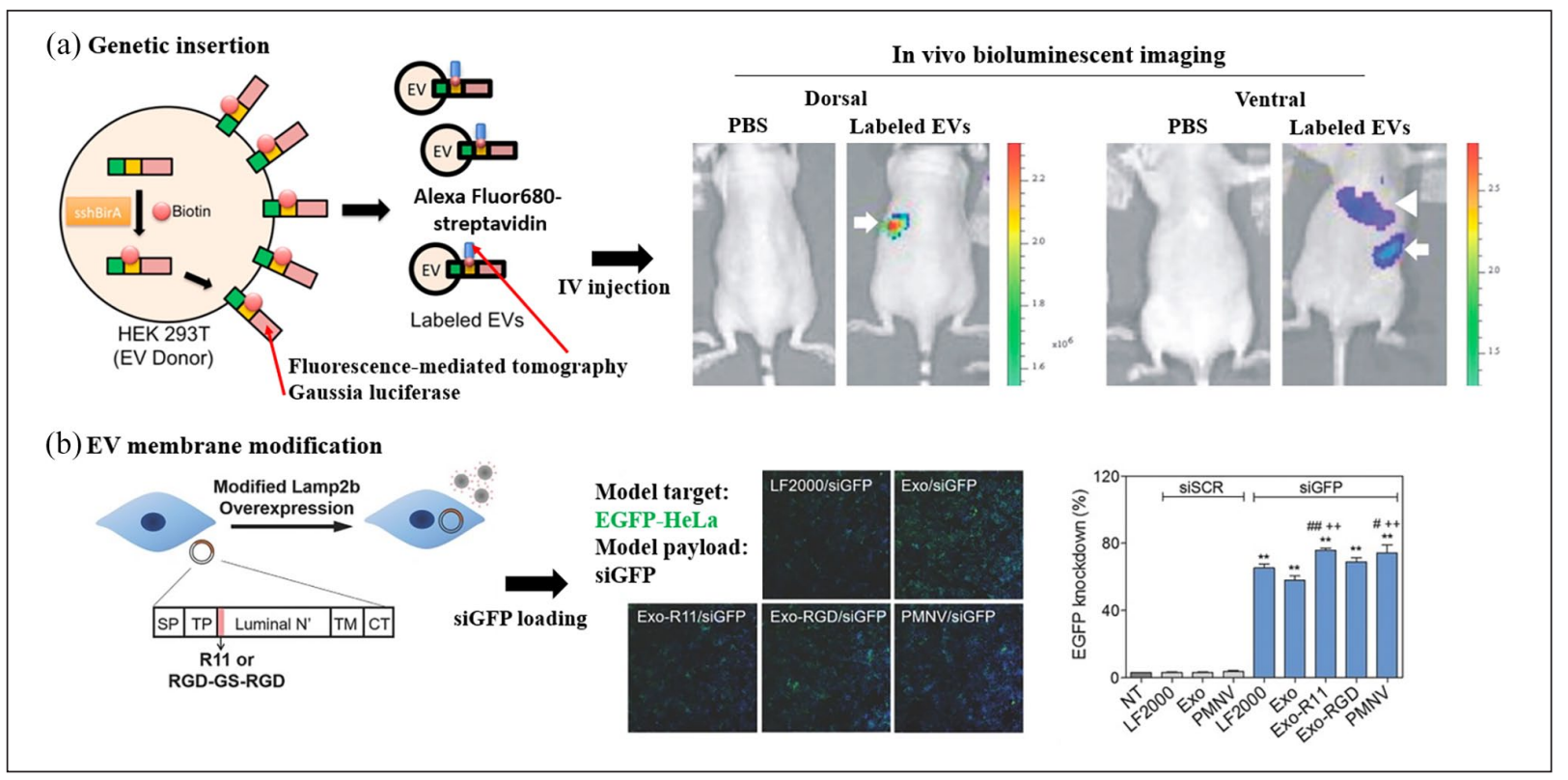

Figure 5. Strategies to enhance the targeting and bio-imaging ability of EVs: (a) genetic modification of EVs by a design of bimodal (luciferase and click-fluorescence) reporter plasmid, and the in vivo imaging confirmed after IV injection and (b) the modification of EVs membrane component (Lamb2) by engineered plasmid (either multiple cell-adhesion peptide RGD or cell-penetrating poly-Arg, RII), showing the payload (siGFP) efficacy by a silenced EGFP in EGFP HeLa model cells. Adapted from Lai et al., ${ }^{61}$ in ACS Nano and by Jin et al. ${ }^{18}$ in Adv Func Mater.

visualization under microscopy, CT, PET-MRI, or SPECT, which has mainly been sourced from the technologies used in different nanoparticles. Regarding this, readers are guided to refer to other well-reviewed articles. ${ }^{27,28}$

On the other hand, the genetic modification of native components of EVs has been newly designed to express a reporter, and the process is relatively biocompatible without using toxic chemicals and has long-lasting imaging ability. ${ }^{61,62}$ For example, the cell membrane was engineered to express Gaussia luciferase reporter, which was fused to a biotin receptor domain ${ }^{61}$ (Figure 5(a)). Thus, the EVs generated from the cells can be monitored both in vitro and in vivo under luminescent or fluorescent microscopy. Gaussia luciferase and metabolic biotinylation were combined to create a sensitive EV reporter (EV-GlucB) for multimodal imaging in vivo, and bioluminescence and fluorescence-mediated imaging on animals showed a predominant localization of intravenously injected EVs in the liver and spleen. In another report, a transgenic inducible GFP EV reporter mouse containing GFP-CD9, a major EV protein component, was designed for the in vivo imaging and tracking of EVs. ${ }^{62} \mathrm{~A}$ transgenic mouse containing a CRE-recombinase inducible CAG promoter-driven GFP-CD9 was crossed to the nestin-Cre-ER ${ }^{\mathrm{T} 2}$ mouse. This highly selective promoter-driven CRE system was injected with tamoxifen to achieve EVs-labeling in astrocytes. The GFP-labeled EVs produced from astrocytes were shown to prove the immunomodulatory roles in vivo. Although the EVs imaging techniques by gene modification during biogenesis have some merits over the post-modification process, the low imaging sensitivity or absolute intensity remains a further issue to overcome.

After local and systemic administration (through intravenous route) of EVs to animal models or human clinical settings (i.e. Myocardial infarction, cancer, osteoarthritis, Parkinson disease, Alzheimer disease, rheumatoid arthritis, spinal cord injury, brain stroke, dental pulp inflammation, skin burn wound healing etc.) according to "clinicalTrials.gov," trapped in non-target organs such as liver, spleen, and lungs with very short half-lives (usually a few to 10 s of minutes). Thus, enhancing the biodistribution and retention of EVs at the lesion area is necessary to enhance the targeting ability and efficacy. Immobilization of polyethylene glycol, charged, or neutral liposome or magnetic nanoparticles is some of the representative examples. ${ }^{56,57}$ Furthermore, strategies to increase cellular entry and intracellular targeting of EVs have been made. For example, cell-penetrating peptides, cationic lipids, $\mathrm{pH}$-sensitive peptides were used to increase the cellular uptake and endolysosomal escape. Indeed, approximately $60 \%$ of internalized EVs could co-localize with lysosomes after $48 \mathrm{~h}$ of contact. ${ }^{58}$ The modification of EVs with cationic lipids and $\mathrm{pH}$-sensitive fusogenic peptides enhanced the disruption of the endolysosomal membrane with the efficient cytosolic release of EVs. ${ }^{59}$ Likewise, the argininerich cell-penetrating peptides could also induce active micropinocytosis and efficient cytosolic release of 
EVs. ${ }^{54,55}$ These methods used in EVs share the key ideas in common with other nanoparticle modification technologies that have long been developed for cellular entry and endosomal escape.

Furthermore, the conjugation of EVs membrane with RGD or specific cell target peptide was proven to be effective. ${ }^{28}$ Apart from the conventional physical or chemical conjugation methods, generic modification has recently gained great interest. Either multiple cell-adhesion peptides (RGD), poly-Arg (R11), or cell-penetrating peptide was inserted into the $\mathrm{N}$-terminus of the Lamp $2 \mathrm{~b}$ protein, which is abundantly expressed on EVs membrane, to facilitate the target-cell binding and intracellular uptake ${ }^{18}$ (Figure 5(b)). Cells were transfected with EVs loading exterior cargo (siRNA) for silencing target model gene, and those expressing RGD and R11 (68.9\% and 75.8\%) significantly improved the knockdown efficiency by $11 \%-$ $18 \%$ than the unmodified wild-type EVs. Specifically, when the siGNAS and siREST were delivered to stem cells via the modified EVs, the osteogenesis and neurogenesis of cells showed a 2-3-fold increase, respectively. Other similar studies on the EVs membrane modification by generic insertion used the $\mathrm{C} 1 \mathrm{C} 2$ domain of milk fat globule-EGF factor 8 protein or the transmembrane domain of PDGFR. ${ }^{70,71}$

One recent intriguing study has focused on the ECM penetration ability of EVs via hyaluronan degradation to enhance the targeting ability. ${ }^{19}$ In this study, PH20 hyaluronidase was inserted on the lipid raft at the EV membrane. The enzymatic ability of the PH20-inserted EVs to penetrating the hyaluronan-rich ECM was more than twice with respect to bare EVs, which led to significant enhancement in the antitumor effects in vitro and in vivo. As witnessed, the genetic manipulation of EVs membrane has shown some promise in enhancing the targeting ability, while the improvement of gene transfection efficiency and risk of viral delivery warrant further studies.

\section{Concluding remarks}

EVs are secreted from cells into microenvironments for cell-cell communications. Thus, one stream of studies has analyzed EVs to interpret the cell-cell interactions and to identify the status of several diseases like cancers. Accumulating evidence over the last years has disclosed that the EVs are diverse in size, payload content, and therapeutic efficacy. Therefore, the other stream of studies, gaining more interest in the regenerative medicine community, has focused on how to collect EVs with high quality and quantity for therapeutic purposes. As discussed, many efforts to tackle the major issues confronted in EVs biogenesis-how to control payload content, how to enhance bioactivity, how to provide targeting and bioimaging ability, and how to generate in large scale for mass production - have been taken by various methods, either during biogenesis or at post-collection stages.
While earlier studies have mainly focused on the modulation of biochemical, molecular cues, such as culture medium ingredients and oxygen tension, more recent works started to utilize the biophysical and mechanical stimuli and $3 \mathrm{D}$ cultures with engineered biomaterials, which are considered to mimic the in vivo tissue conditions (e.g. endothelial cells under cyclic stretch, 3D spheroid cultures for tumor cells) where cells would favor the engineered environments to secrete therapeutically-relevant EVs. One recent study by Yang et al. ${ }^{53}$ introduced a cellular nanoporation method where a focal and transient electrical stimulus was used to generate exosomes carrying transcribed mRNAs and targeting peptides. Compared to conventional bulk electroporation, the nanoporation stimulation could generate more exosomes (50-fold) and a significant increase in mRNA transcripts $\left(10^{3}\right.$-fold $)$, demonstrating the impacts of engineered stimulation of cells in the biogenesis of EVs.

Likewise, the tissue-mimic ex vivo culture systems might help to understand the roles of EVs and the related mechanisms happening in the in vivo tissues. One recent study by Lenzini et al. ${ }^{75}$ has demonstrated the decisive role of ECM in the extracellular journey of EVs, underscoring that the design and recapitulation of the context-dependent tissue-mimic matrix are important for interpreting EVs transport in a specific disease or repair model. The interactive phenomena in the "EV-cell-matrix axis" are thus considered an important area to understand, which will help how to design and engineer the environments for EV-producing cells and ultimately to generate EVs more therapeutically relevant.

While some exemplar studies have shown the effective role of the biophysical and mechanical stimulation in the EVs biogenesis, the mechanisms underlying the events remain largely elusive. "Mechanobiology" would be the right language that can interpret the relationship of biophysical/mechanical stimulation and EVs biogenesis. External matrix and mechanical stimuli are well recognized to transmit toward intracellular and nuclear components through various mechanosensitive machineries (integrins, actin filaments, LINK molecules); including these, some recent highlights on the physical stimuli linked with ion channels and cell metabolism might help to elucidate the mechanistic events in the EVs biogenesis.

As witnessed, the potential and impact that EVs hold in the regenerative medicine area are high, and the technological advances in EVs' biogenesis evolve very rapidly. The emerging technologies in EVs biogenesis to secure controlled payload content and bioactivity and enhance cellular/subcellular targeting and bio-imaging ability, together with the production on a large scale, are envisaged to speed up the clinical translations, as next-generation therapeutics for the treatment of diseased and injured tissues.

\section{Declaration of conflicting interests}

The author(s) declared no potential conflicts of interest with respect to the research, authorship, and/or publication of this article. 


\section{Funding}

The author(s) disclosed receipt of the following financial support for the research, authorship, and/or publication of this article: This research was supported by grants from the National Research Foundation of Korea (NRF) (2020R1A2C1005867, 2018K1A4A3A01064257, 2019R1A6A1A11034536, and 2019R1C1C1002490). The present research was also supported by the research fund of Dankook University for the 2019 University Innovation Support Program.

\section{ORCID iDs}

Jung-Hwan Lee iD https://orcid.org/0000-0001-8678-5459 Jonathan C Knowles iD https://orcid.org/0000-0003-3917-3446 Hae-Won Kim (iD https://orcid.org/0000-0001-6400-6100

\section{References}

1. Kalluri R and LeBleu VS. The biology, function, and biomedical applications of exosomes. Science 2020; 367: eaau6977.

2. Van Niel G, d'Angelo G and Raposo G. Shedding light on the cell biology of extracellular vesicles. Nat Rev Mol Cell Biol 2018; 19: 213.

3. Kim H, Wang SY, Kwak G, et al. Exosome-guided phenotypic switch of M1 to M2 macrophages for cutaneous wound healing. Adv Sci 2019; 6: 1900513.

4. Armstrong JP, Holme MN and Stevens MM. Re-engineering extracellular vesicles as smart nanoscale therapeutics. $A C S$ Nano 2017; 11: 69-83.

5. Huleihel L, Hussey GS, Naranjo JD, et al. Matrix-bound nanovesicles within ECM bioscaffolds. Sci Adv 2016; 2: e1600502.

6. Wang M, Wang C, Chen M, et al. Efficient angiogenesis-based diabetic wound healing/skin reconstruction through bioactive antibacterial adhesive ultraviolet shielding nanodressing with exosome release. ACS Nano 2019; 13: 10279-10293.

7. Gandham S, Su X, Wood J, et al. Technologies and standardization in research on extracellular vesicles. Trends Biotechnol 2020; 38: 1066-1098.

8. Jin Q, Li P, Yuan K, et al. Extracellular vesicles derived from human dental pulp stem cells promote osteogenesis of adipose-derived stem cells via the MAPK pathway. J Tissue Eng 2020; 11: 2041731420975569.

9. Zhao M, Anouz R and Groth T. Effect of microenvironment on adhesion and differentiation of murine $\mathrm{C} 3 \mathrm{H} 10 \mathrm{~T} 1 / 2$ cells cultured on multilayers containing collagen I and glycosaminoglycans. J Tissue Eng 2020; 11: 2041731420940560.

10. Barrett P, Quick TJ, Mudera V, et al. Generating intrafusal skeletal muscle fibres in vitro: current state of the art and future challenges. J Tissue Eng 2020; 11: 2041731420985205.

11. Zhang $\mathrm{H}$ and Lyden D. Asymmetric-flow field-flow fractionation technology for exomere and small extracellular vesicle separation and characterization. Nat Protoc 2019; 14: 1027-1053.

12. Van Der Pol E, Van Gemert MJC, Sturk A, et al. Single vs. swarm detection of microparticles and exosomes by flow cytometry. J Thromb Haemost 2012; 10: 919-930.

13. Witwer KW, Buzás EI, Bemis LT, et al. Standardization of sample collection, isolation and analysis methods in extracellular vesicle research. J Extracell Vesicles 2013; 2: 20360.

14. Konoshenko MY, Lekchnov EA, Vlassov AV, et al. Isolation of extracellular vesicles: general methodologies and latest trends. BioMed Res Int 2018; 2018: 8545347.

15. Le Saux S, Aarrass H, Lai-Kee-Him J, et al. Post-production modifications of murine mesenchymal stem cell (mMSC) derived extracellular vesicles (EVs) and impact on their cellular interaction. Biomaterials 2020; 231: 119675.

16. Jeyaram A and Jay SM. Preservation and storage stability of extracellular vesicles for therapeutic applications. AAPS J 2018; 20: 1-7.

17. Kusuma GD, Barabadi M, Tan JL, et al. To protect and to preserve: novel preservation strategies for extracellular vesicles. Front Pharmacol 2018; 9: 1199.

18. Jin Y, Lee JS, Min S, et al. Bioengineered extracellular membranous nanovesicles for efficient small-interfering RNA delivery: versatile platforms for stem cell engineering and in vivo delivery. Adv Funct Mater 2016; 26: 5804 5817.

19. Hong Y, Nam G-H, Koh E, et al. Exosome as a vehicle for delivery of membrane protein therapeutics, PH20, for enhanced tumor penetration and antitumor efficacy. $A d v$ Funct Mater 2018; 28: 1703074.

20. Huang L, Gu N, Zhang X-E, et al. Light-inducible exosomebased vehicle for endogenous RNA loading and delivery to leukemia cells. Adv Funct Mater 2019; 29: 1807189.

21. Lin $\mathrm{Y}, \mathrm{Wu} \mathrm{J}, \mathrm{Gu} \mathrm{W}$, et al. Exosome-liposome hybrid nanoparticles deliver CRISPR/Cas9 system in MSCs. Adv Sci 2018; 5: 1700611.

22. Fuhrmann G, Chandrawati R, Parmar PA, et al. Engineering extracellular vesicles with the tools of enzyme prodrug therapy. Adv Mater 2018; 30: 1706616.

23. Nakao Y, Fukuda T, Zhang Q, et al. Exosomes from TNF$\alpha$-treated human gingiva-derived MSCs enhance M2 macrophage polarization and inhibit periodontal bone loss. Acta Biomater 2021; 122: 306-324.

24. Kou X, Xu X, Chen C, et al. The Fas/Fap-1/Cav-1 complex regulates IL-1RA secretion in mesenchymal stem cells to accelerate wound healing. Sci Transl Med 2018; 10: eaai8524.

25. Nemec S and Kilian KA. Materials control of the epigenetics underlying cell plasticity. Nat Rev Mater 2021; 6: 69-83.

26. Brennan MÁ, Layrolle P and Mooney DJ. Biomaterials functionalized with MSC secreted extracellular vesicles and soluble factors for tissue regeneration. Adv Funct Mater 2020; 30: 1909125.

27. Tao SC, Guo SC and Zhang CQ. Modularized extracellular vesicles: the dawn of prospective personalized and precision medicine. Adv Sci 2018; 5: 1700449.

28. de Abreu RC, Fernandes H, da Costa Martins PA, et al. Native and bioengineered extracellular vesicles for cardiovascular therapeutics. Nat Rev Cardiol 2020; 17: 685-697.

29. Wiklander OPB, Brennan MÁ, Lötvall J, et al. Advances in therapeutic applications of extracellular vesicles. Sci Transl Med 2019; 11: eaav8521.

30. Wei Y, Shi M, Zhang J, et al. Autologous versatile vesicles-incorporated biomimetic extracellular matrix induces biomineralization. Adv Funct Mater 2020; 30: 2000015. 
31. Kang T, Jones TM, Naddell C, et al. Adipose-derived stem cells induce angiogenesis via microvesicle transport of miRNA-31. Stem cells Transl Med 2016; 5: 440-450.

32. Gray WD, French KM, Ghosh-Choudhary S, et al. Identification of Therapeutic covariant MicroRNA clusters in hypoxia-treated cardiac progenitor cell exosomes using systems biology. Circ Res 2015; 116: 255-263.

33. Almeria C, Weiss R, Roy M, et al. Hypoxia conditioned mesenchymal stem cell-derived extracellular vesicles induce increased vascular tube formation in vitro. Front Bioeng Biotechnol 2019; 7: 1-12.

34. Rocha S, Carvalho J, Oliveira $\mathrm{P}$, et al. 3D cellular architecture affects MicroRNA and protein cargo of extracellular vesicles. Adv Sci 2019; 6: 1800948.

35. Najrana T, Mahadeo A, Abu-Eid R, et al. Mechanical stretch regulates the expression of specific miRNA in extracellular vesicles released from lung epithelial cells. J Cell Physiol 2020; 235: 8210-8223.

36. Xiao F, Zuo B, Wang C, et al. Exosomes derived from cyclic mechanical stretch-exposed bone marrow mesenchymal stem cells inhibit RANKL-induced osteoclastogenesis through the NF-кB signaling pathway. Res $S q$ Epub ahead of print 1 December 2020. DOI: 10.21203/rs.3.rs-115772/v1

37. $\mathrm{Yu} \mathrm{W}, \mathrm{Su} \mathrm{X}, \mathrm{Li} \mathrm{M}$, et al. Three-dimensional mechanical microenvironment enhanced osteogenic activity of mesenchymal stem cells-derived exosomes. Chem Eng J 2020; 417: 128040.

38. Colombo M, Moita C, van Niel G, et al. Analysis of ESCRT functions in exosome biogenesis, composition and secretion highlights the heterogeneity of extracellular vesicles. $J$ Cell Sci 2013; 126: 5553-5565.

39. Böker KO, Lemus-Diaz N, Ferreira RR, et al. The impact of the CD9 tetraspanin on lentivirus infectivity and exosome secretion. Mol Ther 2018; 26: 634-647.

40. Sinha S, Hoshino D, Hong NH, et al. Cortactin promotes exosome secretion by controlling branched actin dynamics. J Cell Biol 2016; 214: 197-213.

41. Messenger SW, Woo SS, Sun Z, et al. A Ca2+-stimulated exosome release pathway in cancer cells is regulated by Munc13-4. J Cell Biol 2018; 217: 2877-2890.

42. Shyong Y-J, Chang K-C and Lin F-H. Calcium phosphate particles stimulate exosome secretion from phagocytes for the enhancement of drug delivery. Colloids Surf B Biointerfaces 2018; 171: 391-397.

43. Iliev D, Strandskog G, Nepal A, et al. Stimulation of exosome release by extracellular DNA is conserved across multiple cell types. FEBS J 2018; 285: 3114-3133.

44. Emam SE, Ando H, Lila ASA, et al. A novel strategy to increase the yield of exosomes (extracellular vesicles) for an expansion of basic research. Biol Pharm Bull 2018; 41: 733-742.

45. Parolini I, Federici C, Raggi C, et al. Microenvironmental $\mathrm{pH}$ is a key factor for exosome traffic in tumor cells. $J$ Biol Chem 2009; 284: 34211-34222.

46. Wang Z, Maruyama K, Sakisaka Y, et al. Cyclic stretch force induces periodontal ligament cells to secrete exosomes that suppress IL-1 $\beta$ production through the inhibition of the $\mathrm{NF}-\kappa \mathrm{B}$ signaling pathway in macrophages. Front Immunol 2019; 10: 1310 .
47. Yu W, Chen C, Kou X, et al. Mechanical force-driven TNF $\alpha$ endocytosis governs stem cell homeostasis. Bone Res 2021; 8: 44 .

48. Ambattu LA, Ramesan S, Dekiwadia C, et al. High frequency acoustic cell stimulation promotes exosome generation regulated by a calcium-dependent mechanism. Commun Biol 2020; 3: 1-9.

49. Hedlund M, Nagaeva O, Kargl D, et al. Thermal-and oxidative stress causes enhanced release of NKG2D ligand-bearing immunosuppressive exosomes in leukemia/lymphoma $\mathrm{T}$ and B cells. PLoS One. 2011; 6: e16899.

50. King HW, Michael MZ and Gleadle JM. Hypoxic enhancement of exosome release by breast cancer cells. BMC Cancer 2012; 12: 1-10.

51. Aubertin K, Silva AK, Luciani N, et al. Massive release of extracellular vesicles from cancer cells after photodynamic treatment or chemotherapy. Sci Rep 2016; 6: 1-11.

52. Jabbari N, Nawaz M and Rezaie J. Ionizing radiation increases the activity of exosomal secretory pathway in MCF-7 human breast cancer cells: a possible way to communicate resistance against radiotherapy. Int J Mol Sci 2019; 20: 3649.

53. Yang Z, Shi J, Xie J, et al. Large-scale generation of functional mRNA-encapsulating exosomes via cellular nanoporation. Nat Biomed Eng 2020; 4: 69-83.

54. Nakase I, Noguchi K, Fujii I, et al. Vectorization of biomacromolecules into cells using extracellular vesicles with enhanced internalization induced by macropinocytosis. Sci Rep 2016; 6: 1-10.

55. Nakase I, Noguchi K, Aoki A, et al. Arginine-rich cell-penetrating peptide-modified extracellular vesicles for active macropinocytosis induction and efficient intracellular delivery. Sci Rep 2017; 7: 1-11.

56. Kooijmans S, Fliervoet L, Van Der Meel R, et al. PEGylated and targeted extracellular vesicles display enhanced cell specificity and circulation time. J Control Release 2016; 224: 77-85.

57. Silva AKA, Luciani N, Gazeau F, et al. Combining magnetic nanoparticles with cell derived microvesicles for drug loading and targeting. Nanomed Nanotechnol Biol Med 2015; 11: 645-655.

58. Heusermann W, Hean J, Trojer D, et al. Exosomes surf on filopodia to enter cells at endocytic hot spots, traffic within endosomes, and are targeted to the ER. J Cell Biol 2016; 213: 173-184.

59. Nakase I and Futaki S. Combined treatment with a pH-sensitive fusogenic peptide and cationic lipids achieves enhanced cytosolic delivery of exosomes. Sci Rep 2015; 5: 1-13.

60. Tabares L and Betz B. Multiple Functions of the vesicular proton pump in nerve terminals. Neuron 2010; 68: 1020-1022.

61. Lai CP, Mardini O, Ericsson M, et al. Dynamic biodistribution of extracellular vesicles in vivo using a multimodal imaging reporter. ACS Nano 2014; 8: 483-494.

62. Neckles VN, Morton MC, Holmberg JC, et al. A transgenic inducible GFP extracellular-vesicle reporter (TIGER) mouse illuminates neonatal cortical astrocytes as a source of immunomodulatory extracellular vesicles. Sci Rep 2019; 9: 3094.

63. Liu Z, Wu C, Zou X, et al. Exosomes derived from mesenchymal stem cells inhibit neointimal hyperplasia by activating the Erk1/2 signalling pathway in rats. Stem Cell Res Ther 2020; 11: 220. 
64. Vining KH and Mooney DJ. Mechanical forces direct stem cell behaviour in development and regeneration. Nat Rev Mol Cell Biol 2017; 18: 728-742.

65. Romani P, Valcarcel-Jimenez L, Frezza C, et al. Crosstalk between mechanotransduction and metabolism. Nat Rev Mol Cell Biol 2021; 22: 22-38.

66. Lee J-H, Kim D-H, Lee H-H, et al. Role of nuclear mechanosensitivity in determining cellular responses to forces and biomaterials. Biomaterials 2019; 197: 60-71.

67. Lee G, Han S-B, Lee J-H, et al. Cancer mechanobiology: microenvironmental sensing and metastasis. ACS Biomater Sci Eng 2019; 5: 3735-3752.

68. LeeJ,HendersonK, MassiddaMW, etal.Mechanobiological conditioning of mesenchymal stem cells for enhanced vascular regeneration. Nat Biomed Eng 2021; 5: 89-102.

69. Romani P, Brian I, Santinon G, et al. Extracellular matrix mechanical cues regulate lipid metabolism through Lipin-1 and SREBP. Nat Cell Biol 2019; 21: 338-347.
70. Hartman ZC, Wei J, Glass OK, et al. Increasing vaccine potency through exosome antigen targeting. Vaccine 2011; 29: 9361-9367.

71. Ohno S-I, Takanashi M, Sudo K, et al. Systemically injected exosomes targeted to EGFR deliver antitumor microRNA to breast cancer cells. Mol Ther 2013; 21: 185-191.

72. Noren Hooten N, Yáñez-Mó M, DeRita R, et al. Hitting the Bullseye: are extracellular vesicles on target? J Extracell Vesicles 2020; 10: e12032.

73. Kamerkar S, LeBleu VS, Sugimoto H, et al. Exosomes facilitate therapeutic targeting of oncogenic KRAS in pancreatic cancer. Nature 2017; 546: 498-503.

74. Syn NL, Wang L, Chow EK-H, et al. Exosomes in cancer nanomedicine and immunotherapy: prospects and challenges. Trends Biotechnol 2017; 35: 665-676.

75. Lenzini S, Bargi R, Chung G, et al. Matrix mechanics and water permeation regulate extracellular vesicle transport. Nat Nanotechnol 2020; 15: 217-223. 